\title{
Five centuries of climate change in Australia: the view from underground
}

\author{
HENRY N. POLLACK, ${ }^{1 *}$ SHAOPENG HUANG ${ }^{1}$ and JASON E. SMERDON ${ }^{2}$ \\ ${ }^{1}$ Department of Geological Sciences, University of Michigan, Ann Arbor, Michigan, USA \\ ${ }^{2}$ Lamont-Doherty Earth Observatory, Columbia University, Palisades, New York, USA
}

Pollack, H. N., Huang, S. and Smerdon, J. E. 2006. Five centuries of climate change in Australia: the view from underground. J. Quaternary Sci., Vol. 21 pp. 701-706. ISSN 0267-8179.

Received 30 January 2006; Revised 14 June 2006; Accepted 19 June 2006

\begin{abstract}
Fifty-seven borehole temperature profiles from across Australia are analysed to reconstruct a ground surface temperature history for the past five centuries. The five-hundred-year reconstruction is characterised by a temperature increase of approximately $0.5 \mathrm{~K}$, with most of the warming occurring in the 19th and 20th centuries. The 17th century was the coolest interval of the five-century reconstruction. Comparison of the geothermal reconstruction to the Australian annual surface air temperature time series in their period of overlap shows excellent agreement. The full geothermal reconstruction also agrees well with the low-frequency component of dendroclimatic reconstructions from Tasmania and New Zealand. The warming of Australia over the past five centuries is only about half that experienced by the continents of the Northern Hemisphere in the same time interval. Copyright (C) 2006 John Wiley \& Sons, Ltd.
\end{abstract}

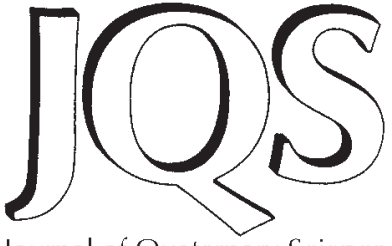

Journal of Quaternary Science

KEYWORDS: palaeoclimate; borehole temperatures; Australia

\section{Introduction}

The global instrumental record of surface air temperature extends back only to ca. 1860 . To place the instrumental record into a longer historical context, traditional climate proxies have been integrated to estimate the variability of the surface air temperature prior to the existence of the instrumental record. These proxies derive from sources such as tree-ring thickness and late-wood density; isotopic chemistry of speleothems, corals and ice; the distribution and composition of pollen; thickness and composition of lacustrine varves; and historical records of agricultural production and sea-ice extent. Over the past few decades a new source of information about the preinstrumental surface temperature history has been developed: the temperature of the rocks beneath the surface of the Earth, as measured in boreholes to depths of a few hundred metres. Here we analyse 57 borehole temperature profiles from across Australia to reconstruct an average ground surface temperature history for the continent over the past five hundred years.

The fundamental concept behind the use of the present-day subsurface temperature field as an archive of past temperature variations at the surface is illustrated with a simple analogy. If a rock is placed near a camp-fire at night, its interior will gradually warm as radiant heat from the campfire diffuses into it. The following morning, long after the campfire has burned out, the interior of the rock will still be warm, offering testimony

* Correspondence to: H. N. Pollack, Department of Geological Sciences, University of Michigan, Ann Arbor, MI 48109, USA.

E-mail: hpollack@umich.edu to the fact that there had recently been a campfire nearby. A careful quantitative analysis of the temperatures in the interior along with the thermal transport properties of the rock can in principle reveal how long and how intensely the fire had burned, in effect recovering the 'climate history' to which the rock had been exposed. In much the same way, ground surface temperature histories at the surface of the Earth are derived from measurements of temperature in the subsurface. Mathematically, the recovery of the ground surface temperature history can be described as determining the time-dependent surface temperature boundary condition that has given rise to an observed subsurface temperature profile. A review of this approach to reconstructing palaeoclimate from subsurface temperatures can be found in Pollack and Huang (2000).

\section{Geothermal studies in Australia}

The measurement of rock temperatures beneath the Earth's surface is a geophysical endeavour undertaken for a number of different purposes. In areas where underground mining is contemplated such measurements can inform ventilation engineers of the magnitude of the refrigeration required for underground operations. In regions under exploration for hydrocarbons, subsurface temperatures provide important clues about the level of hydrocarbon maturity to be anticipated. Scientific determinations of the outward heat flux from Earth's interior are based in part on subsurface temperature measurements. No matter the intended use, such measurements of 
temperature are typically carried out in boreholes drilled either for exploration or development purposes.

In Australia, many thousands of boreholes have been drilled for mineral, hydrocarbon, and hydrological exploration. Subsurface temperatures have been measured in hundreds of these holes for scientific and industrial purposes. Archives of subsurface temperature profiles can be found in several dissertations carried out at the Australian National University under the supervision of J. C. Jaeger, in data collections at Monash University assembled by J. P. Cull, in unpublished records of Geoscience Australia (formerly the Australian Geological Survey Organization), and in an OpenFile Report of the U.S. Geological Survey (Munroe et al., 1975). Long-term effects of Holocene warming following the last glacial maximum have been examined by Cull (1979, 1980), and more recent climate change in southwestern Australia by Appleyard (2005). Here we examine 57 temperature profiles measured in boreholes distributed across Australia, drawn from a global database of borehole temperatures assembled for the purpose of climate reconstruction over the past five centuries (Huang and Pollack, 1998). Profiles in this global database satisfy certain quality control criteria related to smoothness, depth range and sampling density. The locations of these boreholes are listed in Table 1 and displayed in Fig. 1.

\section{Inversion of borehole temperature profiles}

Reconstruction of ground surface temperature history (GSTH) over the past five centuries at each of the sites listed in Table 1 was accomplished by Huang and Pollack (1998) using the Few Parameter Estimation (FPE) technique (Huang et al., 1996; a variant of the Bayesian inversion scheme of Shen and Beck (1991)), in which the GSTH is parameterised in terms of five concatenated century-long trends. Such reconstructions emphasise only the low-frequency variability of the GSTH, and serve as a complement to traditional proxy reconstructions that often display annual resolution.

The inversion of the borehole temperature profile is an operation that transforms a temperature vs. depth profile at a given time (the time of measurement) into a temperature vs. time profile at a given depth, usually the surface, i.e. the inversion yields a GSTH. The link between depth and time is through the thermal diffusivity, a thermophysical property of the rock through which the climate signal is propagating. The borehole temperatures measured at each site, and the fivecentury-long trends recovered from the inversion of the borehole temperature profile are tabulated in the publicly accessible website http://www.ncdc.noaa.gov/paleo/borehole/ borehole.html (Huang and Pollack, 1998).

It is well-known that many factors aside from a changing climate can affect subsurface temperatures. Surface topography, vegetation patterns, hydrological features, subsurface heterogeneity and advective heat transfer, inter alia, imprint a signature on subsurface temperatures. In the sum, these are all site-specific sources of 'noise' that overprint a regional climate change 'signal'. The inversion operation itself embodies some noise suppression parameters, but heavy noise suppression also carries the price of signal suppression as well. An individual GSTH reconstruction, representing both site-specific and regional characteristics, must therefore be interpreted with caution.

A second stage of noise suppression is commonly applied after the individual site inversions have been accomplished, through the averaging of the individual GSTHs over a region, continent or hemisphere (Pollack et al., 1996). This averaging procedure in principle leads to the cancellation or muting of the site-specific perturbations, while bringing out the common climate change signal imprinted on the region. Issues of heterogeneous site distribution and areal weighting must be considered in the averaging operation (Pollack and Smerdon, 2004) to avoid distortion by dense or sparse sampling (many boreholes clustered together or large regions without any boreholes). This second-stage averaging also mutes the small uncertainties associated with different logging dates for each profile.

Because of the need for noise suppression through averaging and the relatively small number of boreholes in the Australian dataset, we present only a continent-wide reconstruction, realised by simple averaging of the 57 individual site reconstructions. This geothermal reconstruction for all of Australia is shown in Fig. 2. The reconstruction is characterised by a temperature at the end of the 20th century that is approximately $0.5 \mathrm{~K}$ warmer than five centuries ago. The $17 \mathrm{th}$ century is the coolest interval of the five-century reconstruction, and may represent an expression of the Little Ice Age recognised widely in the continents bordering the North Atlantic Ocean. The shaded region surrounding the mean reconstruction represents plus or minus one standard error of the mean, and serves as an estimate of the uncertainty associated with the aggregation into a continental mean.

We have investigated the effects of the uneven spatial distribution of data, particularly those associated with site clusters. Table 1 shows several clusters of data; six boreholes are located in the Mt. Isa area alone. To reduce the possibility of overweighting well-represented areas, we formed a local average of each cluster appearing in Table 1, and then used that local average as a 'site' value in forming a continental mean. The continent-wide reconstruction realised in that manner is only trivially different from the simple average of all individual borehole reconstructions. The cluster-adjusted reconstruction lies fully within the uncertainty envelope of the simple average reconstruction. Moreover, the five-century temperature change and the 20th-century trend in both reconstructions are identical and the maximum separation of the two reconstructions, occurring at the end of the 17th century, is only about $0.05 \mathrm{~K}$.

Also shown in Fig. 2 is the annual high-quality Australian surface air temperature (SAT) time series from 1910 to 2004 (Torok and Nicholls, 1996; Della-Marta et al., 2004; http://www.bom.gov.au/cgi-bin/silo/reg/cli_chg/timeseries.cgi), plotted as anomalies relative to its 1961-90 mean. In referencing the borehole reconstruction (GSTH) to the SAT anomaly series, we employ the trend-matching convention of Pollack and Smerdon (2004), modified slightly because the majority of the borehole temperature profiles used in the Australian reconstruction were logged relatively early in the second half of the 20th century (Fig. 3). The dataset has a median logging date in 1972, and $84 \%$ of the boreholes were logged prior to 1976 . Thus many of the borehole measurements were made before the significant surface warming that occurred in Australia in the last few decades of the 20th century; accordingly the boreholes can yield no information about those decades. To accommodate these special temporal characteristics of the Australian dataset, we reference the 20th-century GSTH trend to the SAT trend between 1910 and 1972, by pinning the mean of the 19101972 GSTH trend segment to the mean of the SAT trend over the same interval. The SAT trend is shown as a bold line in Fig. 2. The borehole trend is slightly smaller but clearly compares well with the seven-decade SAT trend. 
Table 1 Principal facts about the boreholes from which the subsurface temperature measurements used in this investigation were obtained

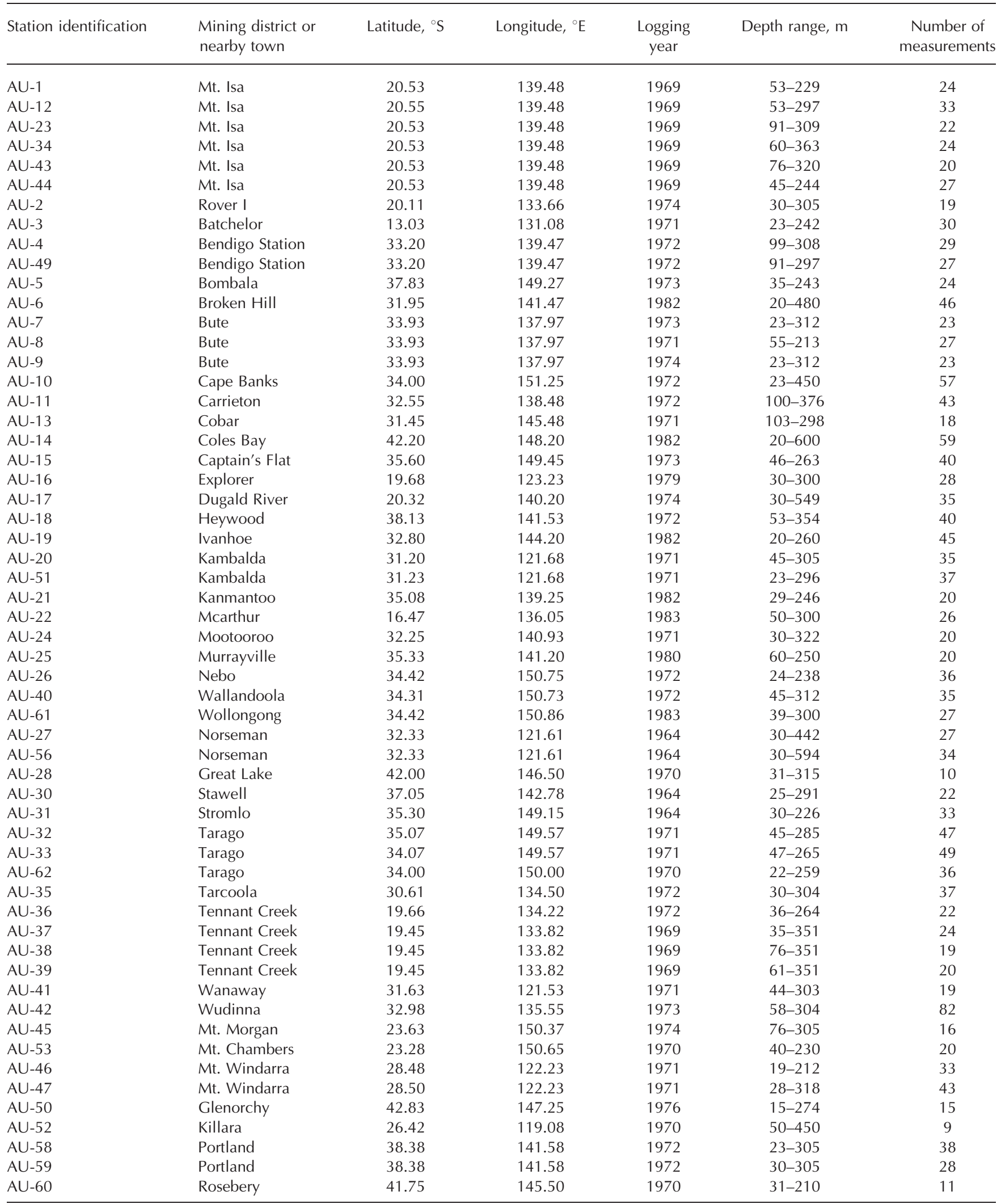

Questions have arisen as to whether the ground surface temperature history is a reliable record of the SAT history on multi-decadal, centennial and longer timescales, because of well-known differences between air and ground temperatures on diurnal and seasonal timescales. The ground surface temperature is an integrated outcome of meteorological, hydrological and biological processes which influence how well ground temperatures can serve as a proxy for air temperatures. Many recent investigations have addressed facets of this issue (see, for example, Beltrami and Kellman, 2003; González-Rouco et al., 2003, 2006; Smerdon et al., 2004, 2006; Bartlett et al., 2004, 2005), with the principal conclusion being that long-period temperature changes in both the SAT and GST appear to be well coupled. The comparison of SAT and GST trends shown in Fig. 2 offer further support for this conclusion. 


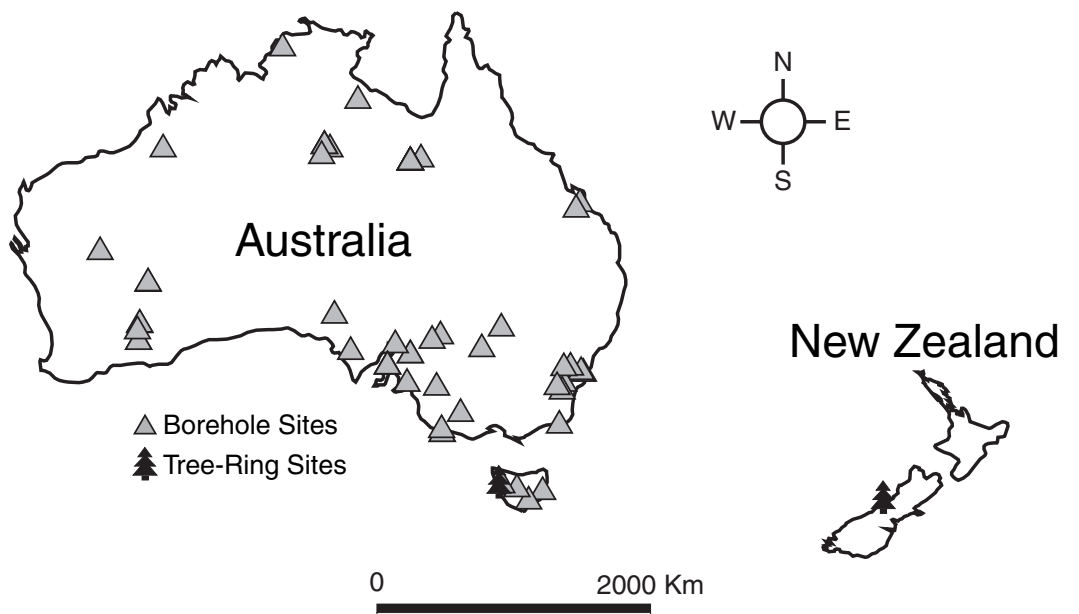

Figure 1 Locations of boreholes from which the subsurface temperature measurements used in this investigation were obtained (see Table 1 for details); and the tree-ring sites of Cook et al. (2000, 2002) referred to in Fig. 4 . Because some boreholes listed in Table 1 have virtually identical locations, they do not appear as separate symbols in the figure

\section{Comparisons with other estimates of climate change in and around Australia}

A recent analysis by Appleyard (2005) of temperature logs from four deep boreholes on the Blackwood Plateau in the Perth Basin (ca. $33.9^{\circ} \mathrm{S} 115.5^{\circ} \mathrm{E}$ ) suggests that there has been a warming of about $0.4 \mathrm{~K}$ between 1500 and the time of logging in the mid-1980s. This estimate is close to, and well within the uncertainty bounds of, the continental reconstruction shown in Fig. 2.

Dendroclimatic reconstructions assembled by Cook et al. (2000) for Tasmania and Cook et al. (2002) for New Zealand (both summarised elsewhere in this volume) provide other comparisons for the borehole reconstruction. These dendroclimatic records, with higher temporal resolution, offer information over a greater spectral range (e.g. annual and multidecadal) than is present in the borehole GSTH. They do,

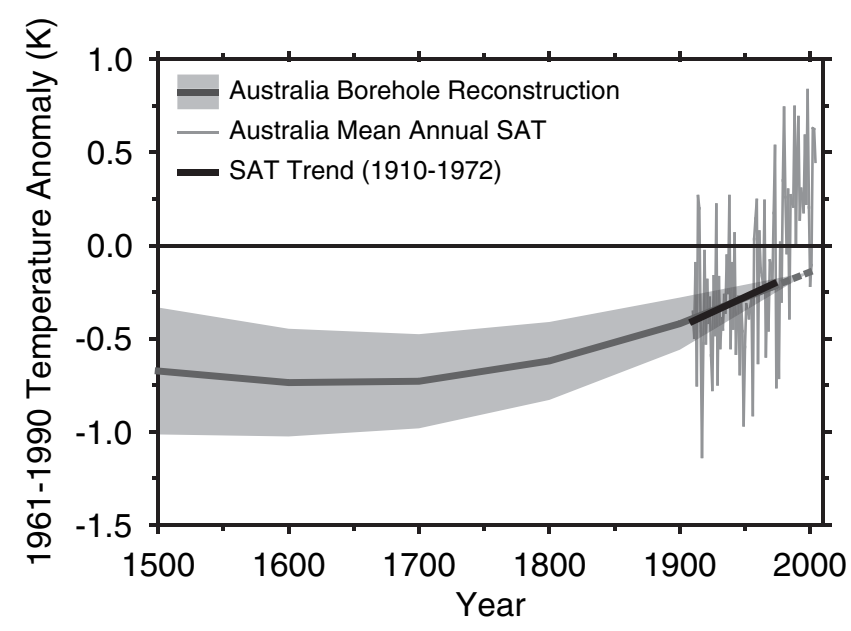

Figure 2 Mean ground surface temperature reconstruction for Australia, and the annual Australian SAT time series from 1910 to 2004 (the SAT time series is plotted as anomalies relative to its 1961-90 mean). The borehole reconstruction is dashed from 1972 to 2000 to indicate that the 20th-century trend derives mostly from measurements acquired prior to 1972 . The shaded region around the borehole reconstruction represents plus or minus one standard error of the borehole mean reconstruction. For comparison, the trend in the Australian SAT time series from 1910 to 1972 is shown by a bold line however, allow a comparison of long-term trends. In Figs 4(a) and (b) the mean Australian borehole reconstruction is shown, overlain on the dendroclimatic reconstructions. Although the borehole reconstruction shows no multi-decadal variability (recall that the inversion has been parameterised to return only century-long trends), it is clear that the boreholes have captured much the same low-frequency variability displayed by the dendroclimatic reconstructions over the five centuries. We note that of the two dendroclimatic reconstructions, Tasmania and New Zealand, only the New Zealand reconstruction employed a relatively new analysis technique to better retain lowfrequency variability in dendroclimatic records (Cook et al., 2002). The slightly better comparison between the borehole and New Zealand reconstructions may indeed stem from this difference. One must of course keep in mind that differences between reconstructions may arise because each reconstruction represents a geographic region that is not co-located with the data distribution of the other.

Farther afield, a climate reconstruction from 40 borehole temperature profiles has been presented for the northern region of South Africa by Tyson et al. (1998). Data from 92 boreholes over a wider region of southern Africa (Botswana, Namibia, Zimbabwe, Zambia, and the data of Tyson et al. in South Africa) have been inverted and tabulated by Huang and Pollack (1998) but not published as an ensemble reconstruction. Tyson et al.

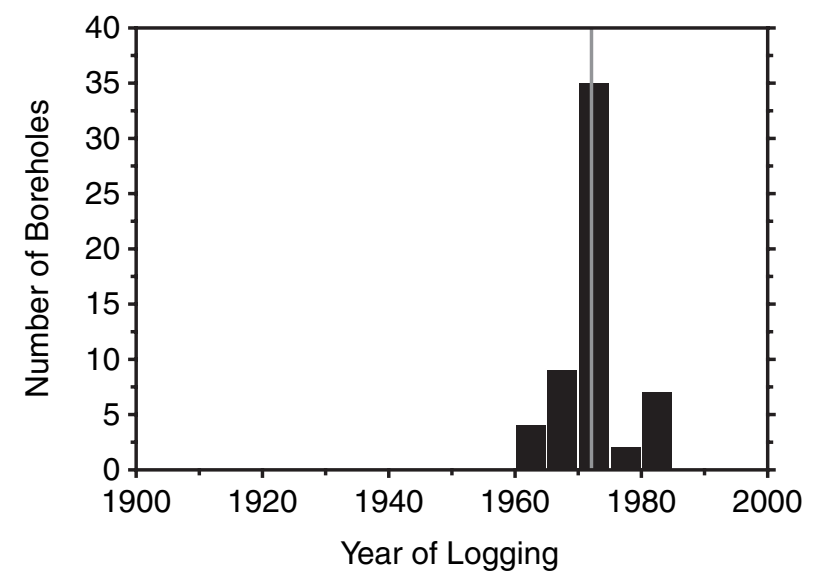

Figure 3 Histogram of borehole logging dates. The median logging date of the 57 borehole temperature profiles used in this investigation is shown by the vertical line 

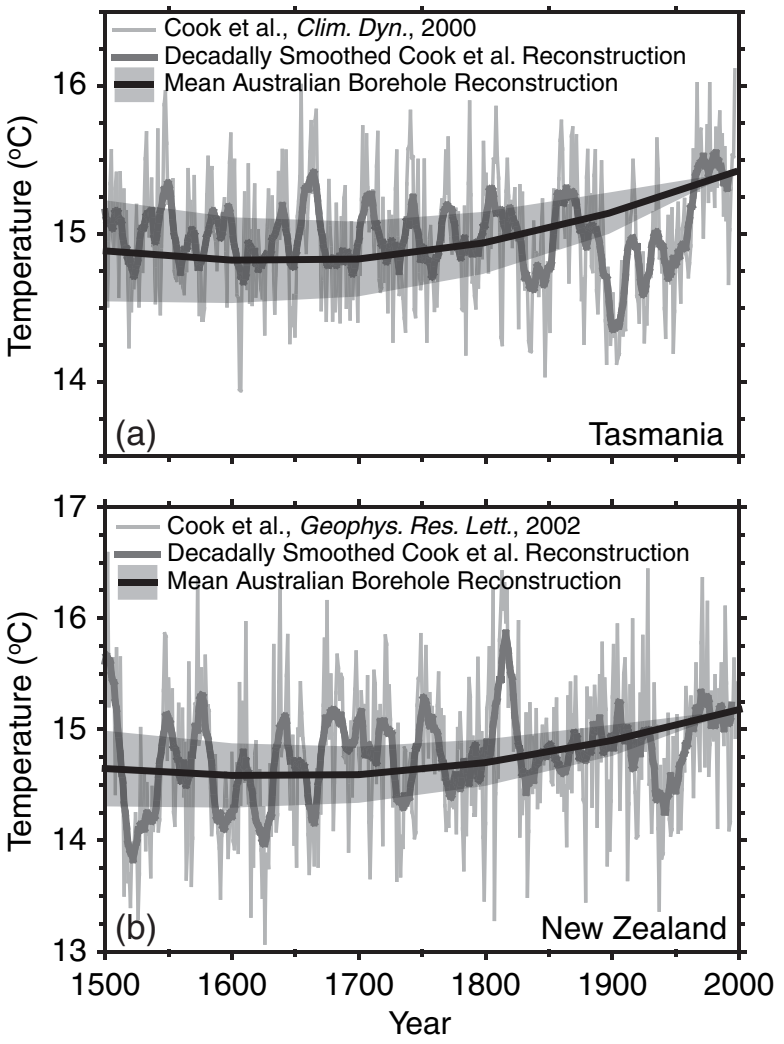

Figure 4 (a) Comparison of Australian borehole reconstruction to dendroclimatological reconstruction from Tasmania. (b) Comparison of Australian borehole reconstruction to dendroclimatological reconstruction from New Zealand

(1998) estimated an increase of the GST by $0.67 \mathrm{~K}$ in the time interval 1861-1980, but did not estimate the GST prior to 1861. The unpublished 92-borehole ensemble for southern Africa shows an increase of $0.4 \mathrm{~K}$ over 1861-1980, but an additional warming of $0.4 \mathrm{~K}$ between 1500 and 1861 . The $0.67 \mathrm{~K}$ warming for South Africa over 1861-1980 estimated by Tyson et al. and the $0.8 \mathrm{~K}$ warming representative of a wider region of southern Africa over five centuries are similar in magnitude, but distributed over different time intervals, a result probably due to different parameterisations of the GSTH in the respective inversions. Both estimates exceed the $0.5 \mathrm{~K}$ five-century warming of Australia.

\section{Comparison of the Australian reconstruction to that of the Northern Hemisphere}

The borehole method of palaeoclimate reconstruction has been applied extensively in the Northern Hemisphere, where many more borehole temperature profiles have become available for analysis. The publicly available database of borehole temperatures (Huang and Pollack, 1998) currently contains 695 and 167 sites in the Northern and Southern Hemispheres, respectively. The Australian dataset comprises about one-third of the Southern Hemisphere representation.

The Northern Hemisphere dataset has been analysed independently by Huang et al. (2000), Harris and Chapman (2001), Beltrami (2002), and Pollack and Smerdon (2004). Although differing in detail, all of these analyses show an essential common characteristic: over the past five centuries

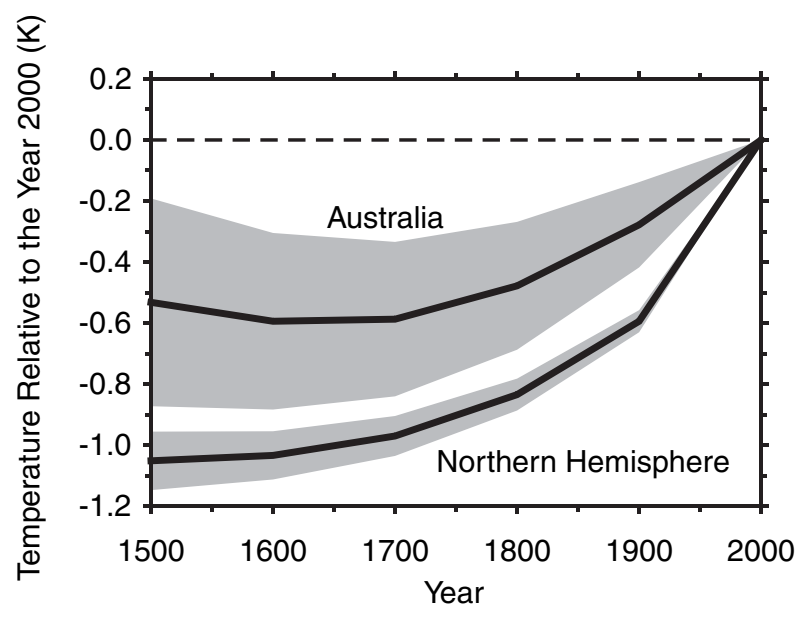

Figure 5 Comparison of Australian borehole reconstruction to Northern Hemisphere borehole reconstruction (Pollack and Smerdon, 2004)

the Northern Hemisphere ground surface has warmed by about $1 \mathrm{~K}$, with half of the warming occurring in the 20th century. This amount of warming is about twice that recorded in the Australian borehole dataset (prior to the significant warming of the last few decades of the 20th century). This contrast is clearly depicted in Fig. 5. Even allowing for the larger uncertainty in the Australian reconstruction (because of the smaller dataset), there is effectively no overlap between the Australian and Northern Hemisphere reconstructions.

\section{Summary and conclusions}

We have analysed 57 borehole temperature profiles from across Australia to reconstruct a ground surface temperature history for the past five centuries. The five-hundred-year reconstruction is characterised by a temperature increase of approximately $0.5 \mathrm{~K}$, with most of the warming occurring in the 19th and 20th centuries. The 17th century was the coolest interval of the five-century reconstruction, perhaps representing a muted expression of the Little Ice Age widely observed in the Northern Hemisphere. Because most of the boreholes were logged prior to 1976, the observed subsurface temperatures do not show the strong warming experienced by Australia in the last two decades of the 20th century. Comparison of the geothermal reconstruction to the high-quality Australian annual SAT time series in their period of overlap shows excellent agreement. The full geothermal reconstruction also shows excellent agreement with the low-frequency component of dendroclimatic reconstructions from Tasmania and New Zealand. The warming of Australia over the past five centuries has been about two-thirds that experienced by southern Africa, and only about half that experienced by the continents of the Northern Hemisphere in the same time interval.

Acknowledgements We thank F. E. M. Lilley and Merren N. Sloan for arranging access to the PhD dissertations of A. E. Beck, L. E. Howard, J. H. Sass and R. Hyndman housed in the library of the Australian National University, and Geoscience Australia and J. P. Cull of Monash University for providing access to unpublished data. E. C. Cook provided the dendroclimatic reconstructions. We are grateful to Steve Appleyard and an anonymous reviewer for their thoughtful reviews. This research was supported in part by U.S. National Science Foundation awards ATM-0081864, ATM-9320004, and ATM-0317572, and the Office of the Vice-President for Research of the University of 
Michigan. J. Smerdon was additionally supported by a Lamont-Doherty Postdoctoral Fellowship from the Lamont-Doherty Earth Observatory of Columbia University.

\section{References}

Appleyard SJ. 2005. Late Holocene temperature record from southwestern Australia: evidence of global warming from deep boreholes. Australian Journal of Earth Sciences 52: 157-162.

Bartlett MG, Chapman DS, Harris RN. 2004. Snow and the ground temperature record of climate change. Journal of Geophysical Research 109: F04008. DOI:10.1029/2004JF000224.

Bartlett MG, Chapman DS, Harris RN. 2005. Snow effect on North American ground temperatures, 1950\&ndash;2002. Journal of Geophysical Research 110: F03008. DOI:10.1029/2005JF000293.

Beltrami H. 2002. Climate from borehole data: energy fluxes and temperatures since 1500. Geophysical Research Letters 29: DOI:10.1029/2002GL015702.

Beltrami H, Kellman L. 2003. An examination of short- and long-term air-ground temperature coupling. Global and Planetary Change 38: 291-303.

Cook ER, Buckley BM, D'Arrigo RD, Peterson MJ. 2000. Warm-season temperatures since $1600 \mathrm{BC}$ reconstructed from Tasmanian tree rings and their relationship to large-scale sea surface temperature anomalies. Climate Dynamics 16: 79-91.

Cook ER, Palmer J, D'Arrigo RD. 2002. Evidence for a 'Medieval Warm Period in a 1,100 year tree-ring reconstruction of past austral summer temperatures in New Zealand. Geophysical Research Letters 29: DOI:10.1029/2001GL014580.

Cull JP. 1979. Climatic corrections to Australian heat-flow data. BMR Journal of Australian Geology and Geophysics 4: 303-307.

Cull JP. 1980. Geothermal records of climatic change in New South Wales. Search 11: 201-203.

Della-Marta PM, Collins DA, Braganza K. 2004. Updating Australia's high-quality annual temperature dataset. Australian Meteorological Magazine 53: 75-93.

González-Rouco JF, von Storch H, Zorita E. 2003. Deep soil temperature as proxy for surface air-temperature in a coupled model simulation of the last thousand years. Geophysical Research Letters 30(21): 2116. DOI:10.1029/2003GL018264

González-Rouco JF, Beltrami H, Zorita E, von Storch H. 2006. Simulation and inversion of borehole temperature profiles in surrogate climates: Spatial distribution and surface coupling. Geophysical Research Letters 33: L01703. DOI:10.1029/2005GL024693.

Harris RN, Chapman DS. 2001. Mid-latitude $\left(30^{\circ}-60^{\circ}\right)$ climatic warming inferred by combining borehole temperatures with surface air temperatures. Geophysical Research Letters 28: 747-750.

Huang S, Pollack HN. 1998. Global borehole temperature database for climate reconstruction. Contributions Series 1998-044, IGBP Pages/ World Data Center A for Paleoclimatologic Data, NOAA/NGDC Paleoclimatology Program, Boulder, Colorado.

Huang S, Shen PY, Pollack HN. 1996. Deriving century-long trends of surface temperature from borehole temperatures. Geophysical Research Letters 23: 257-260.

Huang S, Pollack HN, Shen PY. 2000. Temperature trends over the last five centuries reconstructed from borehole temperatures. Nature 403: 756-758.

Munroe RJ, Sass JH, Milburn GT, Jaeger JC, Tammemagi HY. 1975. Basic data for some recent Australian heat-flow measurements. Open-File Report no. U.S. 76-250, Geological Survey, Reston, Virginia.

Pollack HN, Huang S. 2000. Climate reconstruction from subsurface temperatures. Annual Reviews of Earth and Planetary Sciences. 28: 339-365.

Pollack HN, Smerdon JE. 2004. Borehole climate reconstructions: spatial structure and hemispheric averages. Journal of Geophysical Research 109: D11106. DOI:10.1029/2003JD004163.

Pollack HN, Huang S, Shen PY. 1996. Inference of ground surface temperature history from subsurface temperature data: Interpreting ensembles of borehole logs. Pure and Applied Geophysics 147: 537 550.

Shen PY, Beck AE. 1991. Least squares inversion of borehole temperature measurements in functional space. Journal of Geophysical Research 96: 19 965-19979.

Smerdon JE, Pollack HN, Cermak V, Enz JW, Kresl M, Safanda J, Wehmiller JF. 2004. Air-ground temperature coupling and subsurface propagation of annual temperature signals. Journal of Geophysical Research 109: D21107. DOI:10.1029/2004JD005056.

Smerdon JE, Pollack HN, Cermak V, Enz JW, Kresl M, Safanda J, Wehmiller JF. 2006. Daily, seasonal and annual relationships between air and subsurface temperatures. Journal of Geophysical Research 111: D07101. DOI:10.1029/2004JD005578.

Torok SJ, Nicholls N. 1996. A historical annual temperature dataset for Australia. Australian Meteorological Magazine 45: 251-260.

Tyson PD, Mason SJ, Jones MQW, Cooper GRJ. 1998. Global warming and geothermal profiles: the surface rock temperature response in South Africa. Geophysical Research Letters 25: 2711-2714. 